\title{
Simultaneous Kinetic-Spectrophotometric Determination of Hydrazine and Acetylhydrazine in Micellar Media Using the H-Point Standard Addition Method
}

\author{
Abbas AfKhami ${ }^{\dagger}$ and Ali Reza Zarei \\ Department of Chemistry, Faculty of Sciences, Bu-Ali Sina University, Hamadan, Iran
}

\begin{abstract}
The H-point standard addition method (HPSAM), based on a spectrophotometric measurement for the simultaneous determination of hydrazine and acetylhydrazine, is described. This method is based on the difference between the rates of their reactions with $N, N$-dimethylaminobenzaldehyde (DAB) in the presence of sodium dodecyl sulfate (SDS) in acidic media. The results showed that hydrazine and acetylhydrazine could be determined simultaneously in the range of $0.020-0.70$ and $0.20-5.0 \mathrm{mg} \mathrm{L}^{-1}$, respectively. Under the working conditions, the proposed method was successfully applied to the simultaneous determination of hydrazine and acetylhydrazine in several synthetic mixtures and plasma and water samples.
\end{abstract}

(Received September 5, 2003; Accepted April 19, 2004)

\section{Introduction}

Because of the wide uses of hydrazine derivatives in industry, agriculture pharmaceuticals, antioxidants, polymer additives, explosives and other field on one hand, and their toxicity on the other, their determination is of special interest. Hence, simple, rapid, highly sensitive and accurate methods are required for the determination of trace amounts of hydrazine derivatives in samples.

Several methods have been reported for the determination of hydrazine and hydrazine derivatives. These include titrimetry, ${ }^{1,2}$ potentiometry, ${ }^{3} \quad$ amperometry, ${ }^{4} \quad$ spectrophotometry, ${ }^{5-9}$ chemiluminescence ${ }^{10-12}$ and chromatography. ${ }^{13,14}$

Nowadays, multi component analysis (MCA) by means of spectrophotometry for simultaneous analysis of components has gained a considerable reputation. The simultaneous determination of two or more compounds in the same sample without any previous chemical separation has been developed from several mathematical procedures. For a binary mixture, some of these procedures are based on using absorbance data, such as multivariate calibration, ${ }^{15}$ multiwavelength linear regression analysis, ${ }^{16}$ and other algorithms for extending the pattern recognition methods of a more qualitive nature, such as regression on latent reliable (principle component regression, PCR, and partial least squares, PLS). ${ }^{17}$ Other method uses derivative spectrophotometry, which can potentially make a significant contribution to the determination of mixtures by increasing the selectivity compared to normal spectrophotometry. ${ }^{18}$

The Bosch-Reig et al. method ${ }^{19}$ was aimed at establishing the fundamentals for the application of the HPSAM to kinetic data for the simultaneous analysis of binary mixtures, or to the calculation of analyte concentrations completely free from a bias error. For this purpose, they used two variants of the

\footnotetext{
† To whom correspondence should be addressed.

E-mail: afkhami@basu.ac.ir
}

HPSAM. One was applied when the reaction of one component was faster than that of the other, or the latter did not take place at all; the other was used when the rate constants of the two components were time-dependent.

In this paper, we describe a rapid, simple, precise and accurate method for the simultaneous determination of hydrazine and acetylhydrazine using the H-point standard addition method. This method is based on the difference between the rates of their reactions with $N, N$-dimethylaminobenzaldehyde (DAB) in the presence of sodium dodecyl sulfate (SDS) in an acidic media.

\section{Experimental}

\section{Apparatus}

A Shimadzu Model 3101PC UV-visible recording spectrophotometer with $1-\mathrm{cm}$ glass cells was used for absorbance measurements.

\section{Reagents}

Triply distilled water and analytical-reagent grade chemicals were used. A standard solution of hydrazine $\left(1000 \mathrm{mg} \mathrm{L}^{-1}\right)$ was prepared by dissolving $0.4063 \mathrm{~g}$ of hydrazinium sulfate (Merck) in water and diluting to the mark with water in a $100-\mathrm{mL}$ volumetric flask. A standard solution of acetylhydrazine (1000 $\mathrm{mg} \mathrm{L}^{-1}$ ) was prepared by dissolving $0.1000 \mathrm{~g}$ of acetylhydrazine (Merck) in water and diluting to the mark in a $100-\mathrm{mL}$ volumetric flask. A $0.2 \mathrm{~mol} \mathrm{~L}^{-1} \mathrm{SDS}$ was prepared by dissolving $5.76 \mathrm{~g}$ of SDS (Merck) in water and diluting to the mark in a $100-\mathrm{mL}$ volumetric flask. A $0.02 \mathrm{M}$ DAB solution was prepared by dissolving $0.149 \mathrm{~g}$ of DAB in the $0.2 \mathrm{M}$ SDS and diluting with an SDS solution to the mark in a $100-\mathrm{mL}$ volumetric flask. A $0.2 \mathrm{~mol} \mathrm{~L}^{-1} \mathrm{HCl}$ solution was prepared by diluting concentrated hydrochloric acid.

\section{Procedure \\ Appropriate volumes of hydrazine and acetlhydrazine}




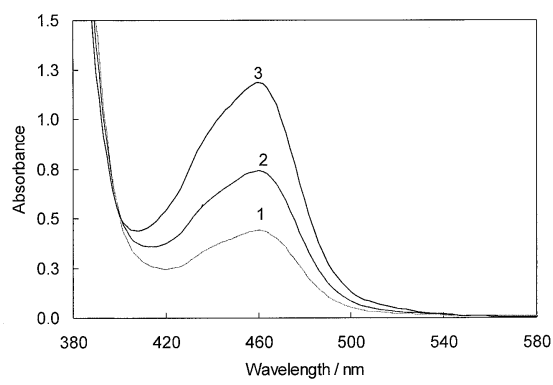

Fig. 1 Absorption spectra of (1) $0.20 \mathrm{mg} \mathrm{L}^{-1}$ hydrazine, (2) $3.0 \mathrm{mg}$ $\mathrm{L}^{-1}$ acetylhydrazine, and (3) their mixture in the presence of 0.002 mol L-1 DAB, $0.02 \mathrm{~mol} \mathrm{~L}^{-1} \mathrm{SDS}, 0.02 \mathrm{~mol} \mathrm{~L}^{-1}$ hydrochloric acid and $60^{\circ} \mathrm{C}$.

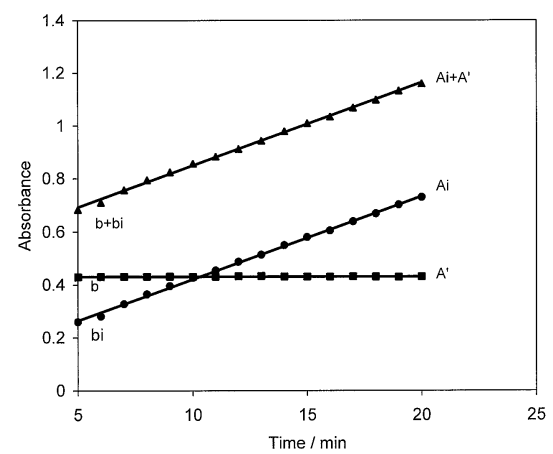

Fig. 2 Absorbance-time curves for a $0.2 \mathrm{mg} \mathrm{L}^{-1}$ hydrazine (ם), 3.0 $\mathrm{mg} \mathrm{L}^{-1}$ acetylhydrazine $(\bullet)$ and their mixture $(\mathbf{\Delta})$ in the presence of $0.002 \mathrm{~mol} \mathrm{~L}^{-1} \mathrm{DAB}, 0.02 \mathrm{~mol} \mathrm{~L}^{-1} \mathrm{SDS}, 0.02 \mathrm{~mol} \mathrm{~L}^{-1}$ hydrochloric acid and $60^{\circ} \mathrm{C}$.

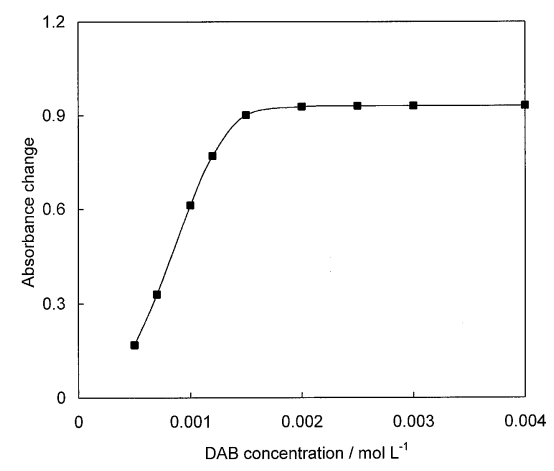

Fig. 3 Effect of the $N, N$-dimethylaminobenzaldehyde (DAB) concentration on the reaction of a mixture of $0.2 \mathrm{mg} \mathrm{L}^{-1}$ hydrazine- $3.0 \mathrm{mg} \mathrm{L}^{-1}$ acetylhydrazine in the presence $0.02 \mathrm{~mol} \mathrm{~L}^{-1}$ SDS, $0.02 \mathrm{~mol} \mathrm{~L}^{-1}$ hydrochloric acid and $60^{\circ} \mathrm{C}$.

standard solutions and $1 \mathrm{~mL}$ of $0.2 \mathrm{~mol} \mathrm{~L}^{-1}$ hydrochloric acid were added into a $10 \mathrm{~mL}$ volumetric flask. The solution was diluted to $c a .9 \mathrm{~mL}$ with water and was placed in a $60^{\circ} \mathrm{C}$ water bath; after $10 \mathrm{~min}, 1 \mathrm{~mL}$ of a $0.02 \mathrm{~mol} \mathrm{~L}^{-1} \mathrm{DAB}$ solution was added to initiate the reaction. A stopwatch was started just after the addition of the DAB solution. The solution was diluted to the mark, and a portion of it was transferred into a 1-cm glass cell to measure the absorbance change with time at $460 \mathrm{~nm}$. Synthetic samples containing different concentrations of hydrazine and acetylhydrazine standard solutions were prepared, and the standard addition of acetylhydrazine (up to $2.5 \mathrm{mg} \mathrm{L}^{-1}$ ) was made. The simultaneous determination of

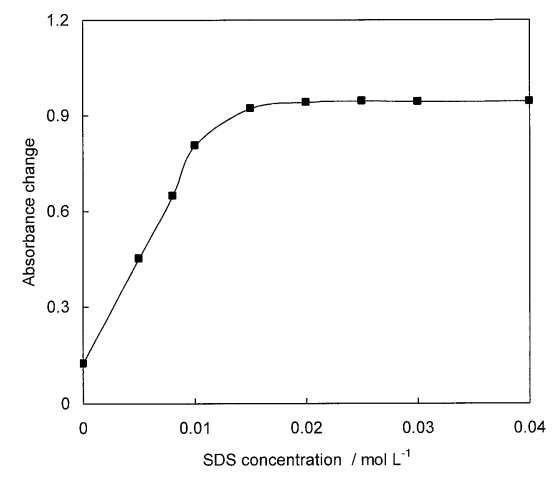

Fig. 4 Effect of the SDS concentration on the reaction of a mixture of $0.2 \mathrm{mg} \mathrm{L}^{-1}$ hydrazine- $3.0 \mathrm{mg} \mathrm{L}^{-1}$ acetylhydrazine in the presence of $0.002 \mathrm{~mol} \mathrm{~L}^{-1} \mathrm{DAB}, 0.02 \mathrm{~mol} \mathrm{~L}^{-1}$ hydrochloric acid and $60^{\circ} \mathrm{C}$.

hydrazine and acetylhydrazine standard solutions with HPSAM was performed by measuring the absorbances at 5 and 20 min after initiation of the reaction for each sample solution. Hydrazine and acetylhydrazine standard solutions, can be determined simultaneously with the concentration ranges of $0.02-0.7 \mathrm{mg} \mathrm{L}^{-1}$ and $0.2-5.0 \mathrm{mg} \mathrm{L}^{-1}$, respectively. The procedure was repeated for some mixtures to show the applicability of the method.

\section{Results and Discussion}

In the SDS micellar medium, the condensation of aromatic aldehydes with hydrazine derivatives afforded color products. The condensation of DAB with hydrazine and acetylhydrazine affording azine and acetylhydrazone products, respectively, proceed according to the following stoichiometric equations:

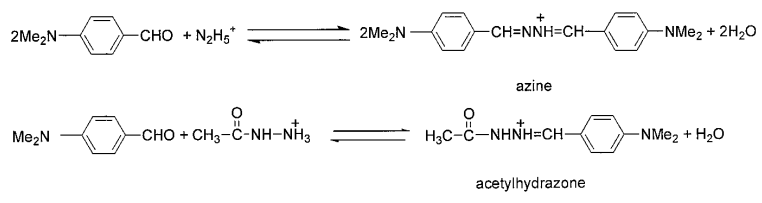

SDS micellar media strongly enhance the rate and equilibrium constants of the above reactions..$^{20}$ As Fig. 1 shows, the spectra of the azine and acetylhydrazone are nearly the same, and each compound interferes in the spectrophtometric determination of the other one. However, it was observed that the reaction of hydrazine with $\mathrm{DAB}$ in the presence of sodium dodecyl sulfate (SDS) in an acidic media was completed at 5 min after mixing, while the reaction of acetylhydrazine with $\mathrm{DAB}$ in the same conditions was relatively slow (see Fig. 2). The reactions could be monitored spectrophotometrically by measuring the absorbance of the solutions at $460 \mathrm{~nm}$. Therefore, the systems seem to be appropriate for the simultaneous determination of hydrazine and acetylhydrazine by using HPSAM.

\section{Effect of variables}

To take full advantages of the procedure, the reagent concentrations and the reaction conditions must be optimized. Various exprimental parameters were studied in order to obtain an optimized system. The parameters were optimized by studying their effects on the reaction of hydrazine and acetylhydrazine mixtures.

The effect of DAB concentration on the rate of the reaction 


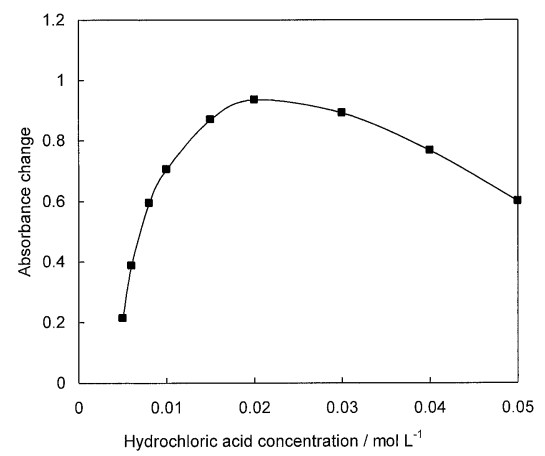

Fig. 5 Effect of the hydrochloric acid concentration on the reaction of a mixture of $0.2 \mathrm{mg} \mathrm{L}^{-1}$ hydrazine- $3.0 \mathrm{mg} \mathrm{L}^{-1}$ acetylhydrazine in the presence of $0.002 \mathrm{~mol} \mathrm{~L}^{-1} \mathrm{DAB}, 0.02 \mathrm{~mol} \mathrm{~L}^{-1} \mathrm{SDS}$ and $60^{\circ} \mathrm{C}$.

was studied over the range $0.0005-0.005 \mathrm{~mol} \mathrm{~L}^{-1}$. The results are shown in Fig. 3. As Fig. 3 shows, the absorbance change for a mixture of hydrazine-acetylhydrazine increased by increasing the $\mathrm{DAB}$ concentration up to $0.0015 \mathrm{~mol} \mathrm{~L}^{-1}$, and remained nearly constant at higher concentrations; therefore, a $0.002 \mathrm{~mol} \mathrm{~L}^{-1} \mathrm{DAB}$ concentration was selected as the optimum concentration.

The effect of SDS concentration on the rate of the reaction was studied in the range of $0.00-0.04 \mathrm{~mol} \mathrm{~L}^{-1}$. The results are shown in Fig. 4. As Fig. 4 shows, the absorbance change for a mixture of hydrazine-acetylhydrazine increased by increasing the SDS concentration up to $0.015 \mathrm{~mol} \mathrm{~L}^{-1}$, and remained nearly constant at higher concentrations; therefore, a $0.02 \mathrm{~mol} \mathrm{~L}^{-1} \mathrm{SDS}$ concentration was selected as the optimum concentration.

The effect of the hydrochloric acid concentration on the rate of the reaction was studied in the range of $0.005-0.05 \mathrm{~mol} \mathrm{~L}^{-1}$. The results are shown in Fig. 5. As Fig. 5 shows, the absorbance change for a mixture of hydrazine-acetylhydrazine increased by increasing the acid concentration up to $0.02 \mathrm{~mol}$ $\mathrm{L}^{-1}$, and decreased at higher concentrations. Therefore, a 0.02 mol $\mathrm{L}^{-1}$ hydrochloric acid concentration was selected as the optimum concentration.

The effect of the temperature on the reactions was studied in the range of $20-90^{\circ} \mathrm{C}$. The results are shown in Fig. 6. As Fig. 6 shows, the absorbance change for a mixture of hydrazineacetylhydrazine increased by increasing the temperature up to $60^{\circ} \mathrm{C}$, and decreased at higher temperatures; therefore, a $60^{\circ} \mathrm{C}$ temperature was selected as the optimum.

\section{Requirements for applying HPSAM}

The basis of using HPSAM for the treating kinetic data under the conditions that the reaction of one component is completed, while that of other component is not completed yet, is described below. ${ }^{18}$ In this case, the variables to be fixed were the times 5 and $20 \mathrm{~min}$, at which the product of the reaction of hydrazine had the same absorbance over the range between these two times, and also there is an appropriate difference between the slopes of the calibration lines.

Considering a binary mixture of hydrazine-acetylhydrazine, for example, assume that, the absorbance of the produced reaction at the reaction of acetylhydrazine with $\mathrm{DAB}$ at $460 \mathrm{~nm}$ at times 5 and $20 \mathrm{~min}$ are $b_{\mathrm{i}}$ and $A_{\mathrm{i}}$, respectively (see Fig. 2), while those of the hydrazine-DAB reaction under the same conditions are $b$ and $A^{\prime}$, respectively. They are equal in this case. The following equations show the relation between them:

(acetylhydrazine) $\quad A_{\mathrm{i}}=b_{\mathrm{i}}+m_{\mathrm{i}} \mathrm{t}_{\mathrm{j}}\left(t_{1} \leq t_{\mathrm{j}} \leq t_{2} ; i=0,1, n, \ldots\right)$

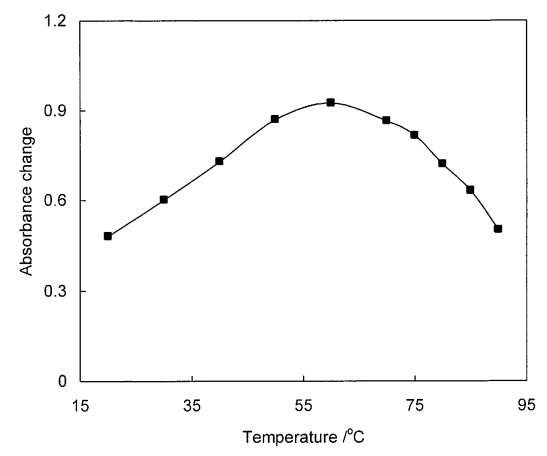

Fig. 6 Effect of the temperature on the reaction of a mixture of 0.2 $\mathrm{mg} \mathrm{L}^{-1}$ hydrazine- $3.0 \mathrm{mg} \mathrm{L}^{-1}$ acetylhydrazine in the presence of 0.002 mol L ${ }^{-1} \mathrm{DAB}, 0.02 \mathrm{~mol} \mathrm{~L}^{-1} \mathrm{SDS}, 0.02 \mathrm{~mol} \mathrm{~L}^{-1}$ hydrochloric acid and $60^{\circ} \mathrm{C}$.

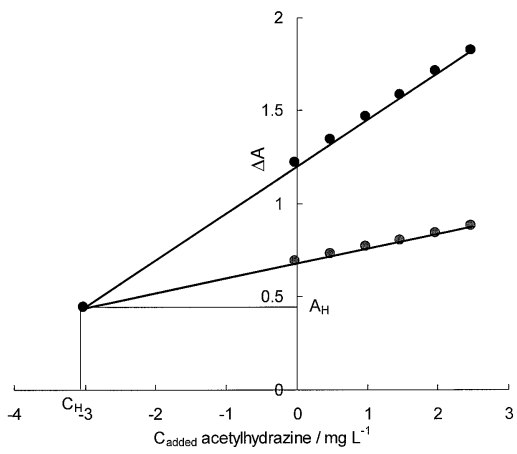

Fig. 7 Plot of HPSAM for the simultaneous determination of a mixture of $0.2 \mathrm{mg} \mathrm{L}^{-1}$ hydrazine- $3.0 \mathrm{mg} \mathrm{L}^{-1}$ acetylhydrazine.

$$
\text { (hydrazine) } \quad A^{\prime}=b+m t_{\mathrm{j}}(m=0) \text {, }
$$

where subscripts $\mathrm{i}$ and $\mathrm{j}$ denote the different solutions for $n$ additions of the acetylhydrazine concentration prepared to apply the HPSAM and for a time comprised in the 5-20 min range, respectively.

Thus, the overall absorbance corresponding to a hydrazineacetylhydrazine mixture at 5 and 20 min were $A_{5}=b_{0}+b_{\mathrm{i}}$ and $A_{20}=A^{\prime}+A_{\mathrm{i}}$, respectively.

Application of the HPSAM at the two aforesaid times gives

$$
\begin{aligned}
& A_{5.0}=b_{0}+b+M_{5} C_{\mathrm{i}}, \\
& A_{20}=A_{0}+A^{\prime}+M_{20} C_{\mathrm{i}},
\end{aligned}
$$

which intersect at point $\mathrm{H}\left(C_{\mathrm{H}}, A_{\mathrm{H}}\right) \equiv\left(-C_{\text {acetylhydrazine }}, A_{\text {hydrazine }}\right)$; Fig. 7. At the intersect,

$$
b_{\mathrm{o}}+b+M_{5.0}\left(-C_{\mathrm{H}}\right)=A_{\mathrm{o}}+A^{\prime}+M_{20}\left(-C_{\mathrm{H}}\right) .
$$

Hence,

$$
-C_{\mathrm{H}}=\frac{\left(A^{\prime}-b\right)+\left(A_{0}-b\right)}{M_{5.0}-M_{20}} .
$$

$A^{\prime}$ and $b$ are equal because of the fast reaction between hydrazine and $\mathrm{DAB}$, hence

$$
-C_{\mathrm{H}}=\frac{A_{0}-b_{0}}{M_{5.0}-M_{20}},
$$


Table 1 Characteristics of calibration graphs for the determination of hydrazine and acetylhydrazine

\begin{tabular}{lccccc}
\hline \multicolumn{1}{c}{ Species } & Slope $/ \mathrm{L} \mathrm{mg}^{-1}$ & Intercept & $\begin{array}{c}\text { Correlation coefficient } \\
(n=11)\end{array}$ & Range/mg L & Limit of detection $/ \mathrm{mg} \mathrm{L}^{-1}$ \\
\hline Hydrazine & 2.0778 & 0.0151 & 0.9996 & $0.02-0.7$ & 0.01 \\
Acetylhydrazine & 0.1668 & -0.0034 & 0.9998 & $0.2-5.0$ & 0.08 \\
\hline
\end{tabular}

a. Defined as $C_{\mathrm{L}}=3 S_{\mathrm{b}} / m$ where $C_{\mathrm{L}}, S_{\mathrm{b}}$ and $m$ are limit of detection, standard deviation of the blank signal, and slope of the calibration graph, respectively. ${ }^{21}$

Table 2 Results obtained by the HPSAM for mixtures of hydrazine and acetylhydrazine

\begin{tabular}{|c|c|c|c|c|c|}
\hline \multirow{2}{*}{$A-C$ equation } & \multirow{2}{*}{$r(n=6)$} & \multicolumn{2}{|c|}{ Spiked/mg L ${ }^{-1}$} & \multicolumn{2}{|c|}{ Found/mg L L ${ }^{-1}$} \\
\hline & & Hydrazine & Acetylhydrazine & Hydrazine & Acetylhydrazine \\
\hline$A_{20}=1.540+0.07716 C_{\mathrm{i}}$ & 0.9991 & 0.70 & 0.20 & 0.71 & 0.21 \\
\hline$A_{5.0}=1.4986+0.0692 C_{\mathrm{i}}$ & $\begin{array}{l}0.9989 \\
0.0092\end{array}$ & & & & \\
\hline $\begin{array}{l}A_{20}=1.628+0.324 C_{\mathrm{i}} \\
A_{5.0}=0.5663+0.1035 C_{\mathrm{i}}\end{array}$ & $\begin{array}{l}0.9992 \\
0.9992\end{array}$ & 0.02 & 5.00 & 0.019 & 4.95 \\
\hline $\begin{array}{l}A_{5.0}=0.9776+0.0745 C_{\mathrm{i}} \\
A_{20}=1.310+0.2445 C_{\mathrm{i}}\end{array}$ & $\begin{array}{l}0.9993 \\
0.9995\end{array}$ & 0.4 & 2.00 & 0.39 & 1.96 \\
\hline $\begin{array}{l}A_{20}=1.278+0.2411 C_{\mathrm{i}} \\
A_{5.0}=1.109+0.0759 C_{\mathrm{i}}\end{array}$ & $\begin{array}{l}0.9986 \\
0.9991\end{array}$ & 0.50 & 1.00 & 0.409 & 1.022 \\
\hline $\begin{array}{l}A_{20}=0.8445+0.202 C_{\mathrm{i}} \\
A_{5.0}=0.7280+0.0728 C_{\mathrm{i}}\end{array}$ & $\begin{array}{l}0.9995 \\
0.9991\end{array}$ & 0.30 & 1.00 & 0.3 & 1.02 \\
\hline $\begin{array}{l}A_{20}=1.446+0.2408 C_{\mathrm{i}} \\
A_{50}=1.3228+0.3290 C_{\mathrm{i}}\end{array}$ & $\begin{array}{l}0.9979 \\
0.9984\end{array}$ & 0.60 & 0.60 & 0.62 & 0.59 \\
\hline $\begin{array}{l}A_{20}=0.9787+0.2108 C_{\mathrm{i}} \\
A_{5.0}=0.3609+0.0548 C_{\mathrm{i}}\end{array}$ & $\begin{array}{l}0.9992 \\
0.9986\end{array}$ & 0.06 & 4.0 & 0.062 & 3.96 \\
\hline $\begin{array}{l}A_{20}=0.6371+0.2428 C_{\mathrm{i}} \\
A_{5.0}=0.5332+0.1244 C_{\mathrm{i}}\end{array}$ & $\begin{array}{l}0.9991 \\
0.9993\end{array}$ & 0.20 & 0.50 & 0.22 & 0.49 \\
\hline
\end{tabular}

which is equivalent to the existing $C_{\text {acetylhydrazine }}\left(=b_{0} / M_{5}=\right.$ $\left.A_{0} / M_{20}\right)$.

Substitution of $C_{\text {hydrazine }}$ into Eqs. (3) and (4) yields $A_{\mathrm{H}}=b$, and the overall equation for the absorbance at $\mathrm{H}$-point simplifies to

$$
A^{\prime}=b=A_{\mathrm{H}}=A_{\text {hydrazine }} \text {. }
$$

The intercept of the straight lines represented by Eqs. (3) and (4) would thus directly yield the unknown acetylhydrazine concentration ( $\left.C_{\text {acetylhydrazine }}\right)$ and the analytical signal of species hydrazine $\left(A_{\text {hydrazine }}\right)$ corresponding to 5 and $20 \mathrm{~s}$ in the original samples. The concentration of hydrazine was calculated from this analytical signal from a calibration graph (Table 1).

According to the theory of the proposed method, the absorbance values for the different mixtures of hydrazine and acetylhydrazine solutions were measured at 5 and $20 \mathrm{~min}$.

A summery of the obtained results for various analyte concentrations is given in Table 2. The concentration was calculated directly by solving a system of equations of two straight lines. The hydrazine concentrations were calculated from the absorbance values $\left(A_{\mathrm{H}}\right)$ obtained from the solution of the cited system of equations.

\section{Accuracy and precision of the method}

Under the optimum conditions, the simultaneous determination of different binary mixtures of hydrazineacetylhydrazine were made using HPSAM. As Table 2 shows, the accuracy of the results is satisfactory when the concentrations of hydrazine and acetylhydrazine vary from $0.02-0.70$ and $0.2-5.0 \mathrm{mg} \mathrm{L}^{-1}$, respectively.

To check the reproducibility of the method, five replicate experiments were performed and the relative standard deviation (RSD) was obtained for mixtures. The results are given in Table 3. As the results show, the precision of the results is satisfactory.

\section{Selectivity}

To study the selectivity of the proposed method, the effect of various ions on the determination of a mixture of $0.2 \mathrm{mg} \mathrm{L}^{-1}$ hydrazine and $3.0 \mathrm{mg} \mathrm{L}^{-1}$ acetylhydrazine was tested under the optimum conditions. The tolerance limit was defined as the concentration of added ion causing less than $a \pm 3 \%$ relative error. The ions $\mathrm{Na}^{+}, \mathrm{K}^{+}, \mathrm{NH}_{4}^{+}, \mathrm{Ba}^{2+}, \mathrm{As}^{3+}, \mathrm{Co}^{2+}, \mathrm{Sn}^{4+}, \mathrm{Mn}^{2+}$, $\mathrm{Zn}^{2+}, \mathrm{Cd}^{2+}, \mathrm{Ni}^{2+}, \mathrm{Fe}^{2+}, \mathrm{Ca}^{2+}, \mathrm{CO}_{3}{ }^{2-}, \mathrm{PO}_{4}^{3-}, \mathrm{SO}_{4}^{2-}, \mathrm{NO}_{3}{ }^{-}, \mathrm{Cl}^{-}, \mathrm{Br}^{-}$ $\mathrm{F}^{-}$and acetate, tartrate and citrate did not interfere even when present in $1000 \mathrm{mg} \mathrm{L}^{-1}$. Phenylhydrazine, urea, semicarbazide, and ammonia did not interfere up to $10 \mathrm{mg} \mathrm{L}^{-1}$.

\section{Application}

To evaluate the proposed methods, it was applied to the simultaneous determination of hydrazine and acetylhydrazine in plasma and water samples. The tested samples were found to be free from hydrazine and acetylhydrazine and thus, synthetic samples were prepared by adding known amounts of hydrazine and acetylhydrazine to the plasma and water samples. The results are given in Table 4. The recoveries are close to $100 \%$, indicating that there is no serious interference in such water samples. The good agreement between these results and known values indicate the successful applicability of the proposed methods for the simultaneous determination of hydrazine and acetylhydrazine. 
Table 3 Results of five replicate experiments for the analysis of hydrazine-acetylhydrazine mixtures

\begin{tabular}{|c|c|c|c|c|c|}
\hline \multirow{2}{*}{$A-C$ equations } & \multirow{2}{*}{$r(n=6)$} & \multicolumn{2}{|c|}{ Spiked/mg L L } & \multicolumn{2}{|c|}{ Found/mg L ${ }^{-1}$} \\
\hline & & Hydrazine & Acetylhydrazine & Hydrazine & Acetylhydrazine \\
\hline $\begin{array}{l}A_{20}=1.210+0.2430 C_{\mathrm{i}} \\
A_{5.0}=0.6873+0.0756 C_{\mathrm{i}}\end{array}$ & $\begin{array}{l}0.9993 \\
0.9994\end{array}$ & 0.20 & 3.00 & 0.21 & 3.12 \\
\hline $\begin{array}{l}A_{20}=1.2435+0.2488 C_{\mathrm{i}} \\
A_{5.0}=0.6796+0.0698 C_{\mathrm{i}}\end{array}$ & $\begin{array}{l}0.9990 \\
0.9993\end{array}$ & 0.20 & 3.00 & 0.21 & 3.15 \\
\hline $\begin{array}{l}A_{20}=1.107+0.2349 C_{\mathrm{i}} \\
A_{5.0}=0.6597+0.0837 C_{\mathrm{i}}\end{array}$ & $\begin{array}{l}0.9986 \\
0.9991\end{array}$ & 0.20 & 3.00 & 0.19 & 2.96 \\
\hline $\begin{array}{l}A_{20}=1.182+0.2391 C_{\mathrm{i}} \\
A_{5.0}=0.6731+0.0791 C_{\mathrm{i}}\end{array}$ & $\begin{array}{l}0.9991 \\
0.9994\end{array}$ & 0.20 & 3.00 & 0.20 & 3.05 \\
\hline $\begin{array}{l}A_{20}=1.193+0.2518 C_{\mathrm{i}} \\
A_{5.0}=0.6527+0.0668 C_{\mathrm{i}}\end{array}$ & $\begin{array}{l}0.9987 \\
0.999\end{array}$ & 0.20 & 3.00 & 0.21 & 2.92 \\
\hline $\begin{array}{l}\text { Mean } \\
\text { Standard deviation } \\
\text { RSD, } \%\end{array}$ & & & & $\begin{array}{l}0.20 \\
0.009 \\
4.50\end{array}$ & $\begin{array}{l}3.02 \\
0.10 \\
3.12\end{array}$ \\
\hline
\end{tabular}

Table 4 Determination of hydrazine and acetylhydrazine mixtures added to water samples using HPSAM

\begin{tabular}{|c|c|c|c|c|c|}
\hline \multirow{2}{*}{ Sample } & \multirow{2}{*}{$A-C$ equation } & \multicolumn{2}{|c|}{ Spiked/mg L ${ }^{-1}$} & \multicolumn{2}{|c|}{ Found/mg L ${ }^{-1}$} \\
\hline & & Hydrazine & Acetylhydrazine & Hydrazine & Acetylhydrazine \\
\hline Drinking water & $\begin{array}{l}A_{20}=1.708+0.2690 C_{\mathrm{i}} \\
A_{5.0}=1.059+0.1024 C_{\mathrm{i}}\end{array}$ & 0.30 & 4.00 & 0.31 & 3.90 \\
\hline Spring water & $\begin{array}{l}A_{20}=0.7331+0.2428 C_{\mathrm{i}} \\
A_{5.0}=0.5393+0.0757 C_{\mathrm{i}}\end{array}$ & 0.20 & 1.20 & 0.21 & 1.16 \\
\hline River water & $\begin{array}{l}A_{20}=0.3302+0.190 C_{\mathrm{i}} \\
A_{5.0}=0.2715+0.08875 C_{\mathrm{i}}\end{array}$ & 0.10 & 0.60 & 0.58 & 0.10 \\
\hline Plasma & $\begin{array}{l}A_{20}=0.4758+0.3044 C_{\mathrm{i}} \\
A_{5.0}=0.2739+0.1074 C_{\mathrm{i}}\end{array}$ & 0.060 & 1.00 & 0.070 & 1.02 \\
\hline Plasma & $\begin{array}{l}A_{20}=1.320+0.2401 C_{\mathrm{i}} \\
A_{5.0}=0.482+0.0760 C_{\mathrm{i}}\end{array}$ & 0.040 & 5.00 & 0.038 & 5.11 \\
\hline Plasma & $\begin{array}{l}A_{20}=0.6302+0.3089 C_{\mathrm{i}} \\
A_{5.0}=0.5281+0.1082 C_{\mathrm{i}}\end{array}$ & 0.20 & 0.50 & 0.21 & 0.51 \\
\hline
\end{tabular}

HPSAM could be used for the simultaneous determination of hydrazine and acetylhydrazine. Simultaneous determination of hydrazine and acetylhydrazine by the proposed method is based on their complexes with DAB in micellar media. The proposed method offers good selectivity, accuracy and precision that can be applied for a wide range of hydrazine and acetylhydrazine concentrations.

\section{References}

1. V. R. Nair and C. G. Nair, Anal. Chim. Acta, 1971, 57, 429.

2. Y. A. Gawargions and A. Beseda, Talanta, 1975, 22, 757.

3. W. R. McBride, R. A. Heny, and S. Skolnik, Anal. Chem., 1951, 23, 890 .

4. C. Zhao, J. F. Song, and J. C. Zhang, Anal. Lett., 2001, 34, 2111.

5. M. I. Evgen'yev, S. Y. Garmonov, I. I. Evgen'yeva, and H. C. Budnikov, Talanta, 1995, 42, 1465.

6. I. N. Papadoyannis, Microchem. J., 1985, 32, 220.

7. M. Yamanaka, T. Sakai, H. Kumagai, and Y. Inoue, J. Chromatogr., A, 1997, 78, 259.

8. A. Afkhami and A. Afshar-E-Asl, Anal. Chim. Acta, 2000, $419,101$.

9. A. Afkhami and A. Afshar Assl, Microchem. J., 2001, 69, 51.
10. C. Zhao, J. F. Song, and J. C. Zhang, Anal. Lett., 2001, 34, 1323.

11. Z. H. Song, L. Wang, and T. Z. Zhao, Anal. Lett., 2001, 34, 399.

12. A. Safavi and M. R. Baezzat, Anal. Chim. Acta, 1998, 358, 121

13. W. Buchberger and W. Aher, J. Chromatogr., A, 1999, 850, 99.

14. M. I. Evgen'ev, I. I. Evgen'eva, and R. N. Ismailova, J. Anal. Chem., 2000, 55, 933.

15. J. Verdu-Andres, F. Bosch-Reig, and P. Campíns-Falco, Analyst, 1995, 120, 299.

16. M. Blanco, J. Gene, H. Iturriaga, S. Maspoch, and J. Riba, Talanta, 1987, 34, 987.

17. D. L. Massart, B. G. M. Vandeginste, S. N. Deming, Y. Michote, and L. Kaufman (ed.) "Chemmometrics: A Textbook", 1998, Elsevier, Amsterdam.

18. T. C. O'Haver and G. L. Green, Anal. Chem., 1976, 48, 312.

19. F. Bosch-Reig, P. Campíns-Flco, A. Sevillano-Cabeza, R. Herreaz-Hernandez, and C. Molins-Legua, Anal. Chem., 1991, 63, 2424.

20. A. K. Yatsimirsky, N. T. Yatsimirskaya, and S. B. Kashina, Anal. Chem., 1994, 66, 2232.

21. D. Perez-Bendito and M. Silva, "Kinetic Methods in Analytical Chemistry", 1988, Ellis Horwood, Chichester. 